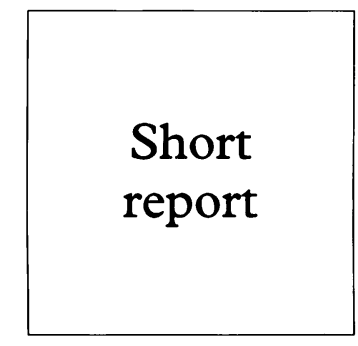

\title{
Semen characteristics in HIV-1 positive men and the effect of semen washing
}

\author{
Ali S Lasheeb, Julie King, Jonathan K Ball, Rebecca Curran, Christopher L R Barratt, \\ Masoud Afnan, Deenan Pillay
}

We have undertaken an analysis of semen from HIV infected men with regard to sperm counts and motility, non-spermatozoal cells, and viral nucleic acid. Regression analysis showed that sperm concentration and motility were positively associated with blood CD4 cell count. By contrast, non-spermatozoal cell concentration (round cells) was inversely related to CD4 count. Extracellular HIV RNA was detected in the majority of semen samples and proviral DNA in a minority. Percoll gradient washing of 12 semen samples yielded six samples containing adequate sperm concentration for analysis. This washing procedure reduced prewash extracellular RNA to below detectable limits in all cases; proviral DNA present in two of the six prewash samples was also reduced to below detectable limits after washing. We conclude that semen washing before artificial insemination may reduce the risk of HIV transmission from an infected man to an uninfected woman. However, further evidence from prospective analyses of such an approach is required.

(Genitourin Med 1997;73:303-305)

Keywords: HIV, transmission; semen, washing; artificial insemination

\section{Introduction}

Sexual intercourse is the most common mode of HIV transmission. An understanding of the virological content of semen, together with the impact of HIV infection on seminal characteristics, is therefore vital.

Some authors have found few differences in ejaculate volume, sperm density, or total sperm output between HIV seropositive and seronegative men. ${ }^{1}$ By contrast, others document an increase dysspermia in infected men, ${ }^{2}$ and a relation between seminal factors and blood CD4 cell count. ${ }^{3}$ There remains some dispute as to whether HIV infection itself decreases fertility. ${ }^{4}$ Nevertheless, it is clear that virus is present in semen. HIV can be demonstrated by culture, immunofluorescence, and polymerase chain reaction (PCR) in seminal fluid and non-spermatozoal cells. ${ }^{167}$ Of interest, the viral load in semen appears unrelated to plasma load or antiretroviral therapy, ${ }^{18}$ suggestive of a privileged compartment (that is, different virological characteristics to blood). More recently, HIV proviral DNA has been detected in spermatozoa and in spermatogonia and spermatids within the testes, ${ }^{5}$ providing some evidence of direct infection of these cells. A demonstration of productive infection of these cells in vitro is awaited.

In an attempt to reduce the risk of HIV transmission through heterosexual intercourse between HIV discordant couples, Semprini et $a l^{10}$ have undertaken sperm purification from infected men, before insemination into their seronegative partners, with no reported cases of viral transmission. However, clearance of virus by this purification technique was assessed by the relatively insensitive HIV antigen detection method, and viral contamination of such cells remains a possibility.

We have undertaken a pilot study to evaluate the feasibility of developing such a semen washing programme as a clinical service. We report our findings with regard to semen characteristics and virological content of semen from HIV infected men, and the impact of Percoll washing on these factors.

\section{Methods}

SUBJECTS

Semen samples were obtained from confirmed HIV-1 infected men by masturbation, and processed within 1 hour of production.

\section{SEMEN ANALYSIS}

Semen factors were analysed according to the World Health Organisation guidelines (WHO) ${ }^{10}$ by microscopy alone. Sperm motility was determined by counting at least 100 spermatozoa at $400 \times$ by phase contrast microscopy. Motility was graded at 0-4 (10) and grade 1-4 was classified as positive for purposes of generating the percentage of motile sperm. Spermatozoa concentration was also assessed on diluted specimens by counting 5-25 large squares of a haemocytometer chamber. ${ }^{10}$ The cellular components were categorised as spermatozoa, epithelial cells, or round cells (immature germ cells and leucocytes). Round cell density was expressed as cells $/ \mathrm{ml}$. No attempt was made to separately identify these subsets by peroxide staining or immunocytochemistry. An aliquot was also stored at $-20^{\circ} \mathrm{C}$ for later virological analysis.

SPERM PURIFICATION

A volume of $0 \cdot 5-1 \mathrm{ml}$ of fresh semen sample was layered on top of an equivalent volume of $80 \%$ Percoll and $40 \%$ Percoll and centrifuged for 20 minutes at $300 \mathrm{~g}$. The supernatant was removed and the pellet suspended with $0.5 \mathrm{ml}$ culture medium and centrifuged for a further 10 minutes at $300 \mathrm{~g}$. The supernatant was 


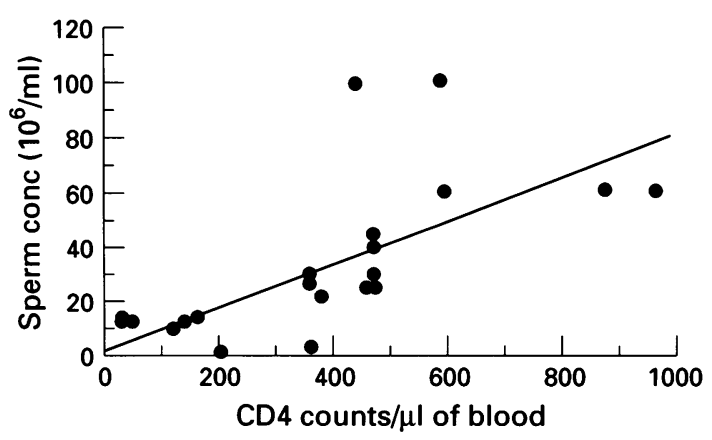

Figure 1 The relation between sperm concentration and CD4 cell counts.

removed and the pellet carefully overlaid with $0.5 \mathrm{ml}$ medium and incubated for 60 minutes at $37^{\circ} \mathrm{C}$ to allow spermatozoa to swim up from the pellet. After this time, $0.25 \mathrm{ml}$ of the upper layer was gently aspirated for seminal analysis, and frozen at $-20^{\circ} \mathrm{C}$ for subsequent virological analysis.

\section{HIV NUCLEIC ACID DETERMINATION}

Pre- and post-wash semen samples stored frozen were allowed to thaw gently, and cells separated from seminal plasma by centrifugation. Extracellular HIV RNA was determined on the consequent supernatant by qualitative nucleic acid sequence based amplification (NASBA). ${ }^{11}$ This is a commercial method which incorporates a system control sequence to demonstrate efficient amplification conditions for each sample tested. This assay has a sensitivity of $\mathbf{5 0}$ genome copies per reaction (Kievits $\mathrm{T}$, personal communication). HIV proviral DNA detection was undertaken on cell pellets from both pre- and post-wash samples. DNA extraction was undertaken on cell pellets using components of a commercial extraction kit (Strategene Ltd), validated for use on seminal fluid cells. The resulting DNA pellets were resuspended in $50 \mu$ of sterile distilled water and DNA concentration and purity measured spectrophotometrically at 260/280 nm. HIV DNA was detected using nested PCR utilising primers complementary to highly conserved regions of the envelope gene, ${ }^{12}$ previously verified by sequencing. Conservation of these sequences across all HIV-1 subtypes was confirmed by genome alignment. Amplification products were resolved using agarose gel electrophoresis and visualised by ethidium bromide staining. This assay has a sensitivity of one copy of genome. A positive result was scored as positive. At least three negative results from separate extracts were required before a specimen was scored negative. Pre- and post-wash specimens were not separated into cellular and extracellular components before freezing, and therefore some cell lysis may have occurred during the freeze thawing, allowing cellular RNA to contaminate the extracellular compartment. Further, we cannot exclude some RNA degradation during storage. Unfortunately, a proportion of samples were not stored according to protocol and these were excluded from nucleic acid analysis.

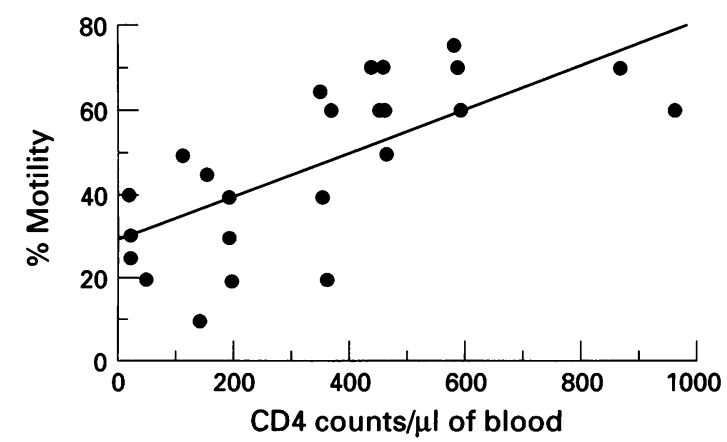

Figure 2 The relation between sperm motility and CD4 cell counts.

STATISTICS

Statistical analysis was undertaken by simple regression analysis, the paired Student's $t$ test $\overrightarrow{0}$ for comparison of groups, and the MannWhitney test.

\section{Results}

Twenty six semen samples were obtained from 16 white HIV positive men ( 14 homosexuals, $\omega$ one haemophiliac, one intravenous drug user). ㅇ They had a median CD4 cell count of $358 \times \vec{~}$ $10^{6} / 1$ (range 30-880) and eight were receiving antiretroviral therapy.

All semen samples were allowed to liquefy for 30 minutes at room temperature before $₫$ analysis. Viscosity was normal $(<2 \mathrm{~cm})$. The $\mathrm{pH}$ of the samples were in the range $7 \cdot 8$ to $8 \cdot 7$ (normal limits) and the volume of ejaculate $0.5-1.0 \mathrm{ml}$. Semen characteristics were as follows: median sperm concentration $22 \times \frac{\circ}{\Phi}$ $10^{6} / \mathrm{ml}$ (range $1 \cdot 2-100 \times 10^{6}$ ), median round cell concentration $3.6 \times 10 \% \mathrm{ml}$ (range $1.2-4.8 \times 10^{6} / \mathrm{ml}$ ) and median sperm motility $50 \%$ (range 10-75\%). Regression analysis demonstrated a positive relation between blood CD4 cell count and both sperm concentration (fig $1 ; R^{2}=0.47, \mathrm{p}<0.0001$ ), and sperm motility (fig $2 ; R^{2}=0.49, \mathrm{p}<0.0001$ ). $\delta$ By contrast, median seminal round cell con- $₹$ centration (including immature germ cells and 은 leucocytes) was higher in those men with CD4 cell counts $<400 / \mu \mathrm{l}\left(4 \times 10^{6} / \mathrm{ml}\right)$ than in those with $\mathrm{CD} 4$ cell counts $>400 / \mu \mathrm{l}(2 \times \mathrm{N}$ $10 \% \mathrm{ml})(\mathrm{p}<0.05)$. There was no relation between any of these factors and antiretroviral therapy (results not shown).

The presence of extracellular HIV RNA and cellular proviral DNA was assessed in $12 \stackrel{\circ}{\circ}$ semen samples from nine donors. RNA was within detectable limits in 10 samples, and 0 proviral DNA within detectable limits in four samples. All four DNA positive samples were also positive for viral RNA. Two individuals $\stackrel{\Phi}{\triangle}$ donated more than two specimens. Of interest, there was concordance within these indi- 8 viduals for RNA but not DNA; in other words, for both these individuals, only one of their samples contained proviral DNA.

Percoll gradient washing was undertaken on all these 12 samples, yielding six post-wash samples with a sperm concentration $>1 \times$ $10 \% / \mathrm{ml}$ and motility $>30 \%$. These six samples were assessed for viral genome. Extracellular 
RNA and cellular proviral DNA were below detectable limits in all these post-wash samples, compared with the presence of viral RNA in all corresponding prewash samples, and viral DNA in two of the prewash samples. This demonstrated the ability of our washing procedure to reduce the levels of viral nucleic acid while maintaining viable spermatozoa (sperm concentration: median $6 \times 10^{6} / \mathrm{ml}$, range $2-10 \times 10 \% \mathrm{ml}$; motility: median $100 \%$, range $50-100 \%)$. Round cells were not detected microscopically in any of our postwash samples.

\section{Discussion}

We demonstrated a clear relation between sperm concentration, motility, round cell concentration, and the degree of immunosuppression in HIV infected men (CD4 cell count) in broad agreement with the other studies which have demonstrated a positive correlation between CD4 count and sperm motility percentage, and an inverse relation with sperm abnormalities. $^{23}$

We identified extracellular HIV RNA in the majority of semen samples, as also described elsewhere. ${ }^{1314}$ This is likely to represent active production of virus from a small reservoir of infected cells. In our study, the semen samples underwent a freeze-thaw step before separation of cells from seminal plasma, and therefore some RNA released from cells may have contaminated extracellular fluid. Nevertheless, this is unlikely to have altered our overall findings, since intracellular RNA will generally represent activation of viral transcription, and therefore production of extracellular virions. Whether or not seminal fluid viral RNA is infectious is unclear, since the success of viral culture from this compartment is $\operatorname{low}^{16}$ and some have argued that cell associated virus, probably within lymphocytes, is more likely to represent the vehicle of sexual transmission. ${ }^{415}$ Our finding that HIV proviral DNA is not consistently detectable in multiple samples from a single individual, suggests variation in the cellular content of semen, although we did not specifically identify different cellular components in this study. It would be interesting to investigate the determinants of such a variation, such as concurrent genital infections, since this may have a bearing on the risk of HIV transmission.

Recently, HIV genome has been detected by in situ PCR in testicular tissue, localised to spermatogonia, spermatids, and spermatocytes although, rarely, macrophages ${ }^{5}$ and HIV DNA has been shown to be present in small numbers of virus incubated normal sperm. ${ }^{9}$ We have attempted to determine the source of semen HIV DNA by separating out the cellular component by Percoll gradient and swim up, therefore purifying the motile sperm. The absence of detectable viral genome in these purified samples supports the supposition that the virus is primarily tropic for leucocytes and other supporting cells rather than spermatozoa, although our numbers are very small.
The undertaking of semen washing before artificial insemination for HIV discordant couples is based on the assumption that this form of purification significantly reduces the viral content of viable sperm, ${ }^{10}$ although, as far as we are aware, no one has hitherto documented the effects of such a procedure on viral RNA and DNA. Our preliminary results suggest that the amount of virus is reduced, although it will never be possible to negate the risk of viral transmission. It is, of course, true that the detection or not of HIV RNA and DNA in this study is determined by the sensitivities of the assays used. Nevertheless, a comparison of prewash and post-wash samples by the same assay does yield useful information with regard to the level of viral genome present. Our results also confirm that semen number and quality are a function of the stage of HIV disease. With regard to artificial insemination, the virological factors of washed semen are only one factor. The risk of intrauterine placement of semen must be considered, as well as the surrounding ethical issues.

We thank the staff and patients at the Whittle Street Clinic, South Birmingham Community NHS Trust and at the South Birmingham Community NHS Trust and at the Department of Sexual Medicine/Department of Infection and
Tropical Medicine, Birmingham Heartlands Hospital, for their Tropical Medicine, Birmingham

Financial support was received from the Mary Crosse Trust Fund

1 Krieger JN, Coombs RW, Collier AC, Koehler JK, Ross SO, Chaloupka $\mathrm{K}$, et al. Fertility parameters in men infected with human immunodeficiency virus. $\mathcal{F}$ Infect $D i$ 1991;164:464-9.

2 Crittenden JA, Handelsman MD, Stewart GJ. Semen analysis in human immunodeficiency virus infection. analysis in human immun

3 Dondero F, Rossi T, D'Offizi G, Sarandrea N, Pinter E, Aiuti F. Semen analysis in HIV seropositive men and in subjects at high risk for HIV infection. Human Reprod 1996;11:765-8.

4 Alexander NJ. Sexual transmission of human immunodeficiency virus: virus entry into the male and female genita tract. Fertil Steril 1990;54:1-18.

5 Nuovo GJ, Becker J, Simsir A, Margiotta M, Khalife G, Shevchuk M. HIV-1 nucleic acids localize to the spermatogonia and their progeny. Am 7 Pathol 1994;144: 1142-8.

6 Vernazza PL, Eron J, Cohen MS, Van der Horst CM Troiani L, Fiscus SA. Detection and biologic characterization of infectious HIV-1 in semen of seropositive men. zation of infectious

7 Hamed KA, Winters MA, Holodniy M, Katzenstein DA, Merigan TC. Detection of human immunodeficiency virus type 1 in semen: effects of disease stage and nucleoside therapy. $\mathcal{F}$ Infect Dis 1993;167:798-802.

8 Liuzzi G, Chiranni A, Bagnarell P, et al. Antiretroviral treatment of men infected with HIV-1 and viral load in semen and saliva samples. XI International Conference on AIDS 1996. Abstract Th.B 4340.

9 Bagastra O, Farzadegan H, Seshamma T, Oakes J, Saah A Pomerantz R. Detection of HIV-1 proviral DNA in sperm from HIV-1 infected men. AIDS 1994;8:1669-74.

10 Semprini AE, Levi-Setti P, Bozzo M, Ravizza M Taglioretti A, Sulpizio P. Insemination of HIV-negative women with processed semen of HIV-positive partners. women with processed sem
Lancet 1992;340:1317-9.

11 Van Gemen B, Kievits T, Nara P, Huisman HG, Jurriaan $\mathrm{S}$, Goudsmit J, et al. Qualitative and quantitative detection of HIV RNA by nucleic acid sequence-based amplifcatoin. AIDS 1993;7:S107-10.

12 Ball JK, Holmes EC, Whitwell H, Desselberger U. Genomic variation of human immunodeficiency virus type 1 (HIV-1): molecular analyses of HIV-1 in sequential blood samples and various organs obtained at sequential Gen Virol 1994;75:867-79.

13 Van Voortis BJ, Martinez A, Majer K, Anderson DJ. Detection of human immunodeficiency virus type 1 in Detection of human immunodeficiency virus type 1 in
semen from seroposotive men using culture and polymerase chain reaction deoxyribonucleic acid amplificamerase chain reaction deoxyribonucleic acid

14 Mermin J, Holodnity $M$, Katzenstein D, Merigan $T$ Mermin J, Holodnity $M$, Katzenstein $D$, Merigan $T$. merase chain reaction. $\mathcal{F}$ Infect Dis 1991;164:769-72.

15 World Health Organisation. Laboratory manual for the examination of human semen and semen-cervical mucu interaction. 2nd rev ed. Cambridge: The Press Syndicate of the University of Cambridge, 1987. 